\title{
LUTAS POR RECONHECIMENTO DOS SURDOS NA INTERNET: EFEITOS POLÍTICOS DO TESTEMUNHO
}

\author{
Regiane L. O. Garcêz
}

Rousiley C. M. Maia

\begin{abstract}
RESUMO
Neste artigo investigamos as oportunidades que a internet favorece para grupos minoritários e marginalizados expressarem-se. Voltamos nossa atenção para a luta pelo reconhecimento empreendida por pessoas surdas e em particular para a representação política das lideranças do movimento social dos surdos e para as contestações em torno das definições de "bem comum" reveladas pelos membros dessa coletividade. Tomamos como material de análise os testemunhos de vida expressos em dois ambientes virtuais diferentes na Internet: o sítio eletrônico de uma associação de surdos - a Federação Nacional de Educação e Integração dos Surdos (Feneis) - e um fórum de discussão de uma rede virtual de relacionamentos (o Orkut). Os testemunhos do sítio da Feneis revelam um discurso público relativamente homogêneo - com definições de bem viver e projeções de metas futuras - que busca demonstrar a existência de um "nós", mediar a formação da opinião e expressar a vontade política. Já a análise do fórum do Orkut mostra que afetados e concernidos, ao discutirem sobre suas aspirações individuais e seus interesses, produzem grande fragmentação sobre detalhes do bem comum. Argumentamos que o uso do testemunho produz diferentes efeitos no que concerne ao intercâmbio de experiências, à defesa da legitimidade das reivindicações e à aprendizagem coletiva, em diferentes ambientes virtuais.
\end{abstract}

PALAVRAS-CHAVE: Internet; reconhecimento; testemunho; surdos.

\section{INTRODUÇÃO}

Diversos estudos têm se dedicado a investigar o uso que atores da sociedade civil fazem da Internet, a fim de construir ações coletivas em torno de causas de interesse comum, mobilizações e ativismo político. Entre esses estudos, um grupo de pesquisadores tem se concentrado em analisar as oportunidades que a Internet oferece para vozes minoritárias ou excluídas expressaremse (MITRA, 2001; PALCZEWSKI, 2001; GUEDES, 2002; LANGMAN, 2005). É amplamente sabido que a Internet proporciona um complexo de conteúdos e informações de toda natureza, sem os obstáculos de acesso nem os filtros provenientes da mídia de massa tradicional. Neste cenário, apesar das barreiras digitais, ela oferece novos recursos e novas oportunidades para que indivíduos e grupos marginalizados ou oprimidos sejam produtores de seus próprios discursos e lutem para que seus anseios e suas demandas ganhem existência pública.

No caso das pessoas surdas e das questões tematizadas por elas, a Internet mostra-se como um meio de expressão particularmente importan- te. Além de se constituírem em uma minoria lingüística, os surdos configuram um público com poucas oportunidades nas grandes arenas de discussão face a face e ainda possuem um segundo obstáculo para a sua participação: a língua. Mesmo que saibam falar, a maioria deles comunica-se por meio da língua de sinais e a participação em fóruns ampliados depende de um tradutor para a língua oral. Nessas situações, há sempre um mediador. Já na Internet, os surdos são os produtores e veiculadores de suas próprias narrativas, sem intermediações.

Neste artigo, partirmos da teoria do reconhecimento, que pressupõe a necessidade de os sujeitos em situação de desvantagem construírem publicamente um entendimento intersubjetivo de justiça, por meio do desenvolvimento de uma linguagem normativa que nomeia essa injustiça, conecta-a a outras experiências de sofrimento, para então estabelecer padrões generalizáveis de demanda e busca por soluções coletivas (TAYLOR, 1992; FRASER, 1997; 2003; HONNETH, 2003). Indagamos, em particular, como os surdos procuram construir e disputar definições de bem comum, 
aquilo que é considerado válido ou justo em suas vidas, por meio da comunicação digital. Para operacionalizar esse estudo, escolhemos focalizar os testemunhos porque essa forma comunicativa é particularmente talhada para permitir a expressão daqueles que sofrem injustiças e que nem sempre encontram formas de vocalizar seu sofrimento. Como propõe Young, "as narrativas são freqüentemente uma ponte, em tais casos, entre a experiência silenciosa de estar injustiçado e argumentos políticos sobre justiça" (YOUNG, 2000, p. 72).

Neste artigo, investigamos o papel que os testemunhos exercem em dois ambientes distintos da Internet. Em primeiro lugar, examinamos como a maior entidade brasileira de surdos - a Federação Nacional de Educação e Integração dos Surdos (Feneis) - mobiliza testemunhos em seu sítio eletrônico oficial (cf. FEDERAÇÃO NACIONAL DE EDUCAÇÃO E INTEGRAÇÃO DOS SURDOS, 2007). A nossa premissa é a de que a associação dos surdos, neste ambiente, constrói um discurso público que reivindica "representar" e "agir em nome" dos surdos brasileiros; ela busca constituir um "nós", exprimir valores e interesses compartilhados, e, assim, construir certa unidade que confere consistência, relativa estabilidade e continuidade à ação coletiva (MELUCCI, 1996; URBINATI, 2000; 2006). Em segundo lugar, investigamos como os próprios surdos ou as pessoas concernidas com a questão da surdez utilizam os testemunhos em um fórum de discussão presente no sítio de relacionamentos Orkut (cf. ORKUT, 2007). A nossa premissa é a de que, nesse ambiente virtual, os indivíduos expressam aspirações e interesses diversos (e algumas vezes rivais) e disputam seus pontos de vista, produzindo fragmentação ao infinito sobre detalhes do bem comum.

Acreditamos que este estudo oferece algumas contribuições relevantes. Em primeiro lugar, a teoria do reconhecimento, apesar de seu amplo escopo filosófico e de suas contribuições originais para tratar o conflito e a mudança social, ainda não concedeu a devida atenção a estudos empíricos. Em segundo lugar, diferentemente de pesquisas sobre vozes de sujeitos marginalizados na Internet, que freqüentemente focalizam apenas um ambiente virtual, nosso interesse é apreender diferentes formas de aplicação da comunicação digital na luta por reconhecimento. Em ter- ceiro lugar, acreditamos que os resultados dessa pesquisa evidenciam que os testemunhos são expressos em meio a uma variedade de formas comunicativas e seus efeitos - no que concerne ao intercâmbio de narrativas, à defesa da legitimidade de uma determinada reivindicação e à aprendizagem coletiva - só podem ser apreendidos pragmaticamente, dependendo do modo pelo qual as pessoas contam, escutam e respondem a essas histórias, numa dada situação.

Este artigo está organizado em quatro partes. Primeiro, revemos brevemente a literatura sobre reconhecimento e testemunhos, considerando a relevância da comunicação digital para a luta por reconhecimento dos surdos. Em seguida, descrevemos as ferramentas metodológicas utilizadas neste estudo. Exploramos o conjunto de testemunhos em diferentes ambientes virtuais na terceira parte. Finalmente, concluímos com uma síntese dos resultados empíricos e discutimos algumas implicações normativas para estudos futuros de comunicação digital de grupos marginalizados.

\section{A LUTA POR RECONHECIMENTO E O VA- LOR DA VISIBILIDADE AMPLIADA PRO- PORCIONADA PELA INTERNET}

A exclusão e opressão que os surdos vivenciam são históricas. Os registros mais antigos sobre pessoas surdas são as passagens do Antigo Testamento que mostram que hebreus, egípcios e romanos já conviviam com os surdos e os consideravam inferiores (SACKS, 1989; PERLIN, 2002). Nas sociedades antigas, os surdos ficavam restritos aos seus lares por vergonha da família ou isolados em asilos, hospitais, celas ou calabouços, como uma forma de "banimento dos indesejados" ou ainda como objeto de compaixão (STROBEL, 2006), fato que ainda perdura. Em 1880 , foi adotado oficialmente o método do oralismo, baseado em intervenções clínicas que prometiam curar ou corrigir a surdez e reabilitar a fala. Desde então foram excluídas todas as possibilidades de uso das línguas de sinais em instituições que recebiam surdos. Como forma de resistência, foram criadas várias associações de surdos no mundo. No Brasil, as primeiras associações surgiram na década de 1950, chegando atualmente a cerca de 100 associações. Em 1987, foi criada a Feneis (Federação Nacional de Educação e Integração dos Surdos), primeira entidade nacional que congrega todas as instituições e associações de surdos e que vem historicamente lutando 
pelo direito ao uso da língua de sinais e da vivência da cultura surda (PERLIN, 1998; 2003; SKLIAR, 1998). A Feneis desenvolve ações em todo o país com a função de auxiliar na criação de novas associações, orientar escolas sobre o uso da Libras (Língua Brasileira de Sinais), promover campanhas de divulgação e esclarecimento sobre a surdez e representar os surdos junto aos órgãos governamentais.

Os testemunhos dos surdos sobre as experiências de preconceito revelam-se uma importante fonte de pesquisa (PERLIN, 2002). Escolhemos analisar essas histórias de vida na perspectiva da teoria do reconhecimento, que considera o conflito como central para a mudança social e ressalta a importância da dimensão intersubjetiva, a fim de se removerem os obstáculos que impedem a auto-realização dos sujeitos subjugados ou oprimidos na sociedade. Taylor (1992) e Honneth (2003) propõem que o reconhecimento é uma necessidade vital para os indivíduos e só é alcançado por meio de uma dinâmica relacional que envolve "se posicionar diante do outro" (TAYLOR, 1992, p. 43-44). Sendo as lutas por reconhecimento intersubjetivamente construídas, o olhar ou a presença do outro, o parceiro de interação, é exatamente o que dá sentido a essas lutas. A rejeição ou a aprovação das pessoas que nos rodeiam fornecem meios para que possamos construir um senso de valor sobre nós mesmos. A partir da internalização do horizonte de expectativas normativas, os sujeitos travam uma luta moralmente motivada para se tornarem membros aceitos por uma coletividade e, portanto, reconhecidos, no que tange à imputabilidade jurídica e ao valor social da suas identidades. À medida que a luta por reconhecimento desenvolve-se, em diferentes âmbitos da vida social - na esfera privada, jurídica e social - ela confronta-se com repetidas negações e desvalorizações, mas, ainda assim, pode alcançar êxito, ao ampliar o horizonte de sentidos compartilhados, oriundos do conflito, numa dada comunidade. Como propõe Honneth, "a reprodução da vida social se efetua sob o imperativo de um reconhecimento recíproco porque os sujeitos só podem chegar a uma autorelação prática quando aprendem a se conceber, da perspectiva normativa de seus parceiros de interação, como seus destinatários sociais" (HONNETH, 2003, p. 155).

A visibilidade ampliada é fundamental para incluir novos valores e novas interpretações na gramática moral de uma determinada comunidade política, a fim de se reconhecerem as necessidades de certos grupos, seus direitos e as contribuições que eles podem oferecer à sociedade: "[...] quanto mais os movimentos sociais conseguem chamar a atenção da esfera pública para a importância negligenciada das propriedades e das capacidades representadas por eles de modo coletivo, tanto mais existe para eles a possibilidade de elevar na sociedade o valor social, ou mais precisamente, a reputação dos seus membros" (idem, p. 208).

É nesse sentido que se justifica nosso interesse em investigar o modo pelo qual a luta por reconhecimento, por meio dos testemunhos, desdobra-se na Internet. Como já apontado, esta oferece múltiplas possibilidades para grupos discriminados promoverem uma redefinição da própria imagem pelos outros e por eles próprios, buscando gerar um novo entendimento simbolicamente compartilhado. A expressão dos testemunhos de vida pode mostrar-se um meio importante para promover essa ponte semântica (idem) entre algo que era desconhecido e que busca a visibilidade e o reconhecimento. Se o indivíduo ou grupo social que sofre o desrespeito consegue revelar o porquê de serem valorizados, pode haver uma eficiente reconstrução de um novo olhar e uma negociação de um novo sentido.

Os testemunhos ${ }^{1}$ são relatos de experiências de vida, experimentadas pelos próprios sujeitos que contam suas histórias e que são, ao mesmo tempo, narradores e protagonistas delas. Eles carregam não apenas o sentido de presenciar, demonstrar, comprovar e declarar ter visto, como também o de vivenciar, julgar e depor. Conforme Seligman-Silva (2006, p. 82), devemos entender o testemunho "na sua complexidade enquanto um misto entre visão, oralidade narrativa e capacidade de julgar: um elemento complementa o outro, mas eles se relacionam também de modo conflituoso". Quando convocados com sentido político, os testemunhos adquirem um tom de julgamento a respeito daquela experiência vivida e um aspecto de defesa de determinado ponto de vista ou de denúncia. Segundo Young (2000), ao

\footnotetext{
1 Segundo Seligmann-Silva (2006), os testemunhos mostram-se como fonte de estudos que vão desde a Psicologia à Filosofia, passando pela Literatura, Teologia e Direito. Em cada uma dessas áreas, o testemunho é definido de uma maneira distinta e pode adquirir tanto o sentido de "prova", "depoimento", "evidência"e "convencimento", quanto o de "sobrevivência", ao fato presenciado e vivenciado.
} 
contar suas histórias, as pessoas de grupos em desvantagem podem conquistar uma escuta solidária para experiências e valores que são distintos daqueles da maioria. No entanto, os testemunhos, como diversos autores já apontaram, podem igualmente ampliar as diferenças entre os grupos em vez de estreitá-las; podem incitar vinganças e reforçar animosidade entre grupos, em vez de motivar a busca por soluções destinadas a mitigar o sofrimento alheio (DRYZEK, 2000; MILLER, 2002). Como pretendemos evidenciar em nosso estudo, os testemunhos são expressos em meio a uma variedade de formas comunicativas e seus efeitos só podem ser apreendidos pragmaticamente, dependendo do modo pelo qual as pessoas contam, escutam e respondem a essas histórias, numa dada situação.

Como seria possível estabelecer uma luta por reconhecimento em um sítio eletrônico de conteúdo estático, que prevê quase nenhuma interatividade? Como considerar a posição do outro, se este outro não se coloca concretamente em relação aos sujeitos que buscam reconhecimento? Como parte que são da dinâmica social, as lutas por reconhecimento perpassam as vidas dos sujeitos coletivos nos mais diversos âmbitos. Em todos eles, os sujeitos buscam desconstruir determinados pressupostos enraizados no horizonte de expectativas daquela sociedade. Nossa premissa é a de que nos sítios institucionais, os conteúdos são estrategicamente planejados e publicados, a fim de combater entendimentos enraizados em um horizonte de expectativas existentes na sociedade, já conhecido pelos surdos. Nos sítios das associações escreve-se para alguém, e esse alguém é um interlocutor presumido ${ }^{2}$, representante daquele horizonte de expectativas contra o qual se quer lutar.

O Orkut $^{3}$, embora seja extremamente voltado para o entretenimento, também pode ceder espaço para os temas políticos. Debates sobre as ques-

\footnotetext{
2 Entendemos que o ato de falar, escrever, enfim, comunicar, pressupõe a existência de um interlocutor, que não precisa ser um interlocutor real, e é por ele que a enunciação é pautada (BAKHTIN, 1986).

3 O Orkut é uma rede social virtual, filiada e mantida pela empresa Google Inc., criada em janeiro de 2004. A rede possuía, até julho de 2008, cerca de 60 milhões de usuários, sendo $54 \%$ deles brasileiros. Vale lembrar que a versão em português só foi criada no início de 2005 . Cerca de $60 \%$ dos usuários têm entre 18 e 25 anos.
}

tões referentes aos surdos são travados por cidadãos ordinários, que produzem narrativas sobre si mesmos diante de um outro que muitas vezes é desconhecido. Contudo, esse outro atua na troca comunicativa como um parceiro concreto. A participação que se dá no Orkut ocorre de maneira assíncrona, mas, por estar em rede e contar com a participação de um sem-número de usuários, sua dinâmica é, em algumas comunidades, efervescente e ininterrupta. Defendemos que a apresentação de testemunhos por meio da conversação nos fóruns do Orkut pode resultar em discussões políticas, recursos essenciais para a luta por reconhecimento e para a troca de razões (MANSBRIDGE, 1999; SCHEUFELE, 2000; WYATT; KATZ \& KIM, 2000; CONOVER; SEARING \& CREWE, 2002; KIM \& KIM, 2008).

\section{METODOLOGIA}

Esta pesquisa adotou duas formas de análise. No caso do sítio eletrônico da Feneis ${ }^{4}$, procuramos mapear todos os conteúdos que expressassem narrativas de vida. Realizamos uma busca em todas as seções do sítio, sem exceções. Depois desse mapeamento, encontramos 25 testemunhos, disponíveis em quatro seções: 1) "De surdo para surdo"; 2) "Matérias de destaque"; 3) "Perfil"; e 4) "Notícias. Em seguida, optamos por analisar os seis textos que trazem testemunhos em primeira pessoa ${ }^{5}$, buscando estabelecer conexões entre as narrativas e os propósitos da entidade, também expressos no sítio, a fim de evidenciar as funções que os testemunhos desempenham em um contexto institucional. Por fim, buscamos elucidar elementos que expressavam um combate a determinados valores e a proposição de novos, organizando esses elementos em categorias comparativas.

No caso do Orkut, fizemos uma busca pelas seguintes palavras-chave: "surdos", "surdo", "Libras", "surdez", "implante coclear" e "língua de

\footnotetext{
4 Todo o mapeamento do sítio da Feneis foi feito entre os dias 7 e 10 de setembro de 2007 .

5 As histórias de vida coletadas eram apresentadas de duas maneiras: em primeira e em terceira pessoa. Em outras palavras, uma parte desse material foi escrita pelas próprias pessoas que vivenciaram experiências para elas importantes e que se dispuseram a expressá-las no ambiente do sítio. A outra parte foi feita em formato de reportagem, em que o jornalista escreve um texto sobre a história de vida de um surdo.
} 
sinais". Nessa busca, encontramos 1915 comunidades. Destas, 836 , ou seja, $44 \%$ eram relacionadas a temas que não diziam respeito em nada à luta dos surdos e foram excluídas. Eliminamos em seguida aquelas comunidades que possuíam menos de 50 participantes, guiados pela lógica de que, quanto mais pessoas, maior a possibilidade de haver uma discussão e, conseqüentemente, maior a possibilidade de manifestação de pontos de vista diferentes. Visitamos os fóruns das 83 comunidades restantes, a fim de selecionar de modo mais cuidadoso as comunidades e os tópicos sobre os quais incidiriam a análise. Inicialmente suprimimos aqueles fóruns com conteúdos comerciais, ofertas de emprego e divulgação de eventos. Escolhemos os debates com maior participação e que envolviam testemunhos. Chegamos, então, a três comunidades. Neste artigo, apresentamos a análise do "Fórum Oralização" (com 283 postagens), presente na comunidade Surdos Oralizados (com 3897 membros).

Preocupamo-nos em caracterizar a comunidade à qual pertencia o fórum, a fim de entender o papel que ela desempenha na definição e na condução dos temas propostos, na característica dos participantes, no conteúdo informacional disponível e no próprio controle interno desses fóruns diante do moderador. O objetivo foi identificar os testemunhos em blocos conversacionais expressos por meio de postagens, sempre em relação aos comentários precedentes e aos comentários suscitados a partir das histórias de vida, assim como fizeram Polletta e Lee (2006) e Black $(2008)^{6}$ em análises de listas de discussão on line. Adotamos os seguintes procedimentos: primeiro, fizemos uma caracterização da discussão, buscando evidenciar as controvérsias - nesse momento, analisamos a conversação como um agregado de temas que se desdobra por meio de uma trajetória própria, identificando os picos do debate, os argumentos apresentados, a participação dos

6 Polletta (2006) busca identificar, na lista de discussão Listening to the City, os momentos em que histórias de vida e razões suscitam opiniões e preferências acerca de transporte, moradia e desenvolvimento econômico depois do ataque de 11 de setembro, além da criação de um memorial em homenagem às vítimas. Já Black (2008) utiliza a mesma lista para analisar como as histórias de vida levam à negociação de identidades entre americanos e estrangeiros. Ambas trabalham com blocos conversacionais que giram em torno das histórias de vida. atores, dentre outros; num segundo momento, apontamos alguns valores a serem desafiados pelas lutas por reconhecimento e valores a serem considerados, organizando esses elementos também em categorias comparativas. Todos os nomes dos participantes do sítio e do fórum de discussão do Orkut foram substituídos por nomes fictícios ${ }^{7}$.

Para operacionalizar a comparação, utilizamos as seguintes variáveis: 1) intercâmbio de narrativas, que diz respeito tanto à função do testemunho de articular afinidades coletivas entre membros de uma coletividade que passam pelas mesmas experiências quanto à de contrapor experiências que entram em choque; 2) demanda, que trata da utilização do testemunho como politizador de situações, por meio de um apelo para que os demais aceitem certas demandas ou que reconheçam determinadas orientações valorativas; 3 ) aprendizagem coletiva, dizendo respeito ao uso das histórias para desvelar conhecimentos novos ou diferentes formas de interpretação de sentidos pré-concebidos numa dada configuração social.

\section{O SÍTIO INSTITUCIONAL: HISTÓRIAS DE VIDA SEMELHANTES, DISCURSOS HO- MOGÊNEOS}

Sítios eletrônicos de grupos que sofrem injustiças frequentemente fornecem elementos para a luta por reconhecimento, na medida em que informam, esclarecem questões controversas e combatem estigmas ou preconceitos. A informação pode servir para pautar discussões sociais ou engendrar novos sentidos na esfera pública. Pode também arregimentar novas pessoas para suas lutas ou fornecer a imagem de uma instituição consolidada. Entre as múltiplas funções cumpridas por um sítio institucional, a publicação de histórias de vida permite compartilhar experiências, sensibilizar opiniões, apresentar pontos de vista que muitas vezes não conseguem ser expressos por meio de argumentos, e promover aprendizado coletivo.

Os seis testemunhos, relatados em primeira pessoa, que coletamos no sítio da Feneis (2007), apresentam histórias de vida bem diferentes. Há um padre surdo, uma pedagoga, um analista de sistemas, uma estudante de gastronomia, uma

\footnotetext{
${ }^{7}$ Na análise do sítio, mantivemos o nome do Padre Vicente por ser uma figura bastante conhecida no Brasil.
} 
professora de Letras e uma pessoa surda-cega que não relatou sua profissão e que faz trabalhos voluntários com surdo-cegos como ela. São profissões, trajetórias e histórias de vida diferentes, mas que guardam entre si muitas semelhanças.

\section{IV.1. Intercâmbio de narrativas: histórias de su-} peração

O primeiro e mais evidente ponto em comum entre os testemunhos dos surdos apresentados no sítio é que eles revelam constrangimentos comuns e histórias de superação. Em todas as narrativas, períodos difíceis deram lugar a histórias de sucesso. A ênfase não está nas dificuldades sofridas, mas na superação dessas dificuldades. O Padre Vicente, por exemplo, relata os desafios de um seminarista surdo ainda na década de 1940 . Uma das principais surpresas para ele é que, além de falar, os estudantes da época deveriam saber latim: "Entrei no Seminário Santo Antônio em 1935, quando foi aberto para receber apenas 21 alunos. Minha primeira surpresa foi descobrir que, além da língua portuguesa, era obrigatório o curso de Latim. Tínhamos o desafio de estudar todo o primeiro semestre para sermos admitidos no primeiro ano do próprio Seminário Menor, onde os estudos duravam seis anos".

Depois de estudar e passar pelo processo necessário para tornar-se padre, Vicente deparou-se com outro desafio: conseguir a autorização do Papa para ser ordenado. Padre Vicente relata, em tom emocionado, que visitou o Papa e obteve a autorização: "Fiquei muito feliz. [...] então, comecei a me preparar para voltar ao Brasil, a Juiz de Fora, marcando para o dia 22 de setembro de $1951 \mathrm{mi}$ nha primeira missa. E foi onde tudo começou e aqui estou com muita alegria, até os dias de hoje".

Os testemunhos encontrados no sítio da Feneis são bastante positivos, assim como o do Padre Vicente. A narrativa apresentada por João é bastante entusiasmada, com exaltação do sucesso, expressa no próprio título do texto, "Surdo, batalhador e conquistador de uma grande vitória": "[...] tenho apenas 21 anos e a causa da minha surdez foi quando eu tinha 10 meses, era bebê, peguei uma meningite muito forte, então só tinha um jeito para sobreviver: tomar antibiótico. Sobrevivi só que perdi a audição, quase morri, mas agora estou completamente feliz, pois me formei no curso de Tecnologia em Informática com ênfase em Análise de Sistemas, da Universidade Carioca, começarei a fazer pós-graduação em curso de especialista em Tecnologia e Segurança de Rede de Computadores e trabalho na empresa Sociedade de Ensino Superior Estácio de Sá, na área de Informática. Lembrei uma coisa que jamais esquecerei. Houve um momento inesquecível na hora da cerimônia de formatura, quando o Orador falou que sou uma pessoa esforçada, brincalhão, lutador, surdo. $\mathrm{E}$ todos os presentes no auditório bateram palmas bem alto. Foi inacreditável! Me emocionei, tenho uma grande conquista e continuarei caminhando para vencer e vencer".

A semelhança entre os problemas experimentados pelos surdos pode ser encontrada nos testemunhos da estudante de gastronomia, Juliana, a primeira gastrônoma surda do país, e da pedagoga Silvia: os obstáculos de comunicação, o empenho da família, a luta para conseguir intérprete na faculdade e os momentos da superação. Em todos os seis testemunhos, a superação está diretamente relacionada à oportunidade de estudo e ao sucesso profissional - dois valores praticamente inquestionáveis na nossa sociedade. Segundo Honneth (2003), a busca por estima social desenvolve-se a partir da consonância entre as características e as realizações individuais e o referencial valorativo compartilhado por uma determinada comunidade de valores: são estimados aqueles que podem contribuir, de alguma maneira, com os objetivos comuns a esse grupo de pessoas.

A luta por reconhecimento expressa no sítio tem como alvo o "outro presumido", que concebe o surdo como incapaz, com atrasos cognitivos e impossibilitados de avançar em uma profissão que exige maior estudo. Para alcançarem a estima social, eles buscam engendrar o entendimento de que a surdez não os impede de exercer as mais diversas tarefas e que, portanto, podem contribuir com os objetivos dessa sociedade. Ao evidenciar a premissa de que os surdos podem exercer quaisquer atividades assim como os ouvintes, a instituição rebate a crença de que surdos são capazes apenas de executarem atividades braçais e de estudarem apenas o suficiente para exercerem esse tipo de trabalho.

\section{IV.2. A defesa da legitimidade de determinada reivindicação:a língua de sinais}

Além do intercâmbio de narrativas, o contar histórias é, freqüentemente, um meio de conferir significado às experiências particulares e às reivindicações consideradas fundamentais que podem não ser devidamente compreendidas por ou- 
tros membros da sociedade: "O testemunho freqüentemente provê uma resposta a pessoas que duvidam da legitimidade da reivindicação da necessidade ou do direito" (YOUNG, 2000, p. 74). Cabe destacar que as narrativas, por si só, não garantem a legitimidade de uma determinada reivindicação. A legitimidade advém da justificação baseada em princípios gerais, passíveis de serem compreendidos e aceitos por outros (DRYZEK, 2000; FORST, 2007). Contudo, ao compartilhar experiências, necessidades ou problemas, os testemunhos de vida são responsáveis pelo processamento de questões éticas enraizadas no cotidiano das pessoas. Os testemunhos sustentam, assim, determinadas reivindicações de justiça que podem vir a ser explicitadas para sustentar uma demanda geral - sejam elas demandas para igual tratamento legal, para proteção à integridade cultural, para combater desvantagens ou, ainda, para a redistribuição de oportunidades e recursos necessários ao bem-estar de um determinado grupo.

Nos testemunhos coletados no sítio da Feneis, as dificuldades existem e transparecem em maior ou menor grau, dependendo do testemunho, ainda que não sejam o foco da narrativa. Para o padre, a dificuldade era a de ser ordenado por causa da surdez. $\mathrm{O}$ analista de sistemas esteve à beira da morte por causa de uma doença. Já a estudante de gastronomia e a professora tiveram problemas para obter intérpretes de Libras na faculdade e em outros ambientes profissionais. Segundo Miriam, professora de Libras da Universidade Federal do Rio de Janeiro: "De 1996 até hoje, não pude mais continuar meus estudos devido às dificuldades que tenho com a minha segunda língua, ou seja, com a Língua Portuguesa e também a Língua Inglesa. Fato que dificulta muitíssimo o acompanhamento das aulas e também a participação em Fóruns, Encontros, Congressos, em discussões existentes nas Universidades, além de dificultar também o acompanhamento nas reuniões do Departamento de Lingüística, em que eu também sou docente. Muitas vezes paguei do meu próprio bolso intérpretes da Feneis para me atenderem e também contei com auxílio de meus alunos do curso de Libras I que possuíam um pouco de conhecimento para interpretar e para me ajudar em atividades relacionadas às minhas aulas inaugurais nos cursos de Libras do ensino de graduação".

Os sucessivos testemunhos exercem nitidamente a função de comprovar e atestar que a au- sência de intérpretes de Libras é prejudicial para a educação dos surdos e para a sua inserção no ambiente de trabalho, além de outras dificuldades experimentadas para desfrutar de bens e serviços. Esses testemunhos mostram que não bastou o reconhecimento legal da Libras (cf. BRASIL, 2002) e que ainda há muito o que fazer em diversos setores da sociedade. Assim, as histórias de vida, muitas vezes, politizam situações e revelam a necessidade de certas medidas coletivas para eliminar obstáculos que impedem a inclusão social desses sujeitos como membros integrais da sociedade (HONNETH, 2003, p. 360). Os testemunhos podem, assim, articular a imediaticidade da experiência com discursos gerais de justificação, sustentando reivindicações gerais: "Somente no ano de 2002, com muita luta e esforço, a Língua de Sinais foi reconhecida como língua oficial dos surdos, por meio da Lei da Libras n. 10 436. Apesar de ter conseguido essa vitória, ainda há muitas metas a serem atingidas em escolas e universidades públicas para que se tenham professores surdos, Mestres ou Doutores, também para que se tenham intérpretes de Libras, assim como professores bilíngües, para atuarem em salas de aula em todas as áreas, para que o surdo sinta tranqüilidade em seus estudos, pois a primeira língua dos surdos é a Libras".

Miriam encerra o seu depoimento com um apelo pela melhoria da educação dos surdos e pelo respeito aos direitos dessa minoria lingüística: “Até quando os surdos brasileiros vão esperar pela garantia do direito à sua língua natural da Libras e aos serviços de intérpretes de Libras? É um $A B$ $S U R D O$ o que reivindicamos? Queremos respostas e ações". Nesse caso, as histórias de vida não são contadas com fins de divertimento ou revelação, mas para demonstrar, descrever, explicar ou justificar alguma coisa aos outros. Isso evidencia que "abrir a deliberação a histórias de vida legitima um tipo de discurso que é emocional, engajado e baseado em particularidades da experiência" (POLLETTA \& LEE, 2006, p. 700). Existem enraizadas fortemente a premissa e a crença de que a Libras é uma língua inferior, incompleta e incapaz de transmitir todos os conteúdos. Muitos nem sequer a consideram um sistema lingüístico, mas, sim, um código superficial. Dessa maneira, o sítio expressa o entendimento da língua de sinais como um código lingüístico completo com o mesmo status de língua. A luta por reconhecimento nesse caso é para que se entenda que a comu- 
nicação espaço-visual é tão valorosa e merecedora de respeito quanto as outras línguas existentes. A língua de sinais garante a auto-realização das pessoas surdas: é um direito garantido juridicamente e que deve, portanto, ser devidamente considerado nas políticas públicas.

\section{IV.3. Aprendizagem coletiva: o orgulho de ser surdo}

Os testemunhos podem ajudar a promover diversas formas de aprendizagem coletiva. Como Polletta e Lee discutem (2006, p. 709), as pessoas entendem uma história ao transitar entre os eventos descritos, os estados emocionais dos protagonistas que estão experimentando esses eventos, e, ainda, o contexto mais amplo construído pela história. Esse processo é particularmente importante para a conquista da estima social, já que, segundo a teoria do reconhecimento, os sujeitos devem promover uma redefinição da própria imagem para si mesmos e também frente aos outros. Nesse sentido, as narrativas podem servir para explicar por que determinados símbolos e práticas têm valor para algumas pessoas e não para outras. Assim sendo, não é de se espantar que os testemunhos publicados no sítio da Feneis sejam entrecortados por exaltação das capacidades dos surdos e do orgulho da própria forma de vida. É uma maneira de a instituição valorizar, de um lado, os sujeitos surdos como capazes de agir e viver com as mesmas perspectivas de futuro que uma pessoa ouvinte e, de outro, o esforço que foi despendido por eles para alcançarem esse sucesso.

Como apontando anteriormente, a língua de sinais é defendida como uma forma válida de comunicação e um elemento definidor de uma identidade e de uma cultura, das quais se tem muito orgulho. Quando a pedagoga Silvia diz: "Sou surda. E com todo orgulho!"; ou quando o analista de sistemas João afirma: "Estou realmente muito orgulhoso pelo que eu batalhei, e ainda estou batalhando, com muita garra, mostrando que a surdez não faz mal a ninguém", eles reafirmam a surdez não como uma deficiência, mas como um modo de viver digno de consideração. Expressar o orgulho de ser surdo é mais uma forma de evidenciar a superação.

Há uma contestação implícita do entendimento que se tem sobre a surdez e da língua de sinais como "anormais". O fato de se comunicarem por meio da língua de sinais não é, de maneira alguma, uma forma de "anormalidade". O adjetivo “normal” é empregado em vários depoimentos para caracterizar modos de vida diferentes, mas considerados como válidos e dignos de valor. João afirma: "Sou capaz e vivo uma vida comum como toda a humanidade vive. Me comunico, por meio da Libras e leitura labial, com meus pais, irmãos, amigos e no trabalho etc., mas tenho de enfrentar os obstáculos e as dificuldades de várias maneiras. Arrisco, busco os novos conhecimentos sempre mais e cada vez melhor e observo o que está faltando para acabar discriminação no Brasil. Muitas vezes quem é ouvinte não entende a diferença da cultura dos surdos e não respeitam [...]".

Juliana, a estudante de gastronomia, após relatar sua infância tranqüila, também reforça essa idéia de normalidade na vida de pessoas surdas: "Minha adolescência foi normalíssima, tendo toda a atenção e orientação, principalmente de minha mãe, que também me esclareceu sobre a sexualidade e sempre me deu liberdade para perguntar o que fosse necessário, para que nunca fosse surpreendida".

O mais surpreendente dos casos é a história de Sonia, surda e cega, é um dos relatos mais surpreendentes. Ela perdeu a audição aos seis anos e a visão aos dezenove. No seu depoimento, ela também enfatiza a trivialidade do seu cotidiano: "O meu dia-a-dia é normal. Faço de tudo em casa, como: fazer comida, lavar louça, passar roupa. Desenvolvo bem trabalhos manuais, inclusive crochê. E gosto de nadar também. Entretanto, dependo de uma pessoa para me passar as informações que estão sendo ditas na televisão ou na rua. Enfim em todos os lugares. Contudo não considero essa situação como uma barreira na minha vida".

Ao demonstrar o orgulho de ser surdo e de ter uma vida normal usando a língua de sinais, os surdos revelam a premissa de que a surdez não deve ser entendida como uma falta, uma barreira ou uma deficiência. Esses surdos possuem rotinas comuns como as de qualquer outra pessoa, tais como desenvolver tarefas domésticas, vivenciar o período da adolescência e se comunicar com seus familiares. O testemunho, além de buscar comprovar que determinado modo de vida deve ser considerado como digno e valoroso, também promove certo julgamento ao defender essa maneira de viver. A cultura surda e o orgulho de ser surdo são mencionados como formas de vida que devem ser reconhecidas como válidas em vez de serem taxadas como inferiores. 
IV.4. Algumas conclusões a partir da análise do sítio da Feneis

A análise do sítio da Feneis evidencia, numa visão de conjunto, a homogeneidade não apenas entre as opiniões, mas também entre os próprios testemunhos: ênfase nas histórias de superação; dificuldades mencionadas apenas com o objetivo de revelar o êxito do desafio superado; defesa da língua de sinais, da cultura e do orgulho de ser surdo. O sítio da Feneis, como um instrumento de comunicação criado estrategicamente para dar visibilidade, tematizar questões e mobilizar novos adeptos, tende a publicar conteúdos que sustentem e legitimem o posicionamento da instituição. Nesse processo, a associação filtra e refina a pluralidade de aspirações, opiniões e perspectivas de uma dada coletividade, enquadra valores, estipula metas futuras e projeta um "nós" no conjunto de relações mais amplas da sociedade (MELUCCI, 1996; URBINATI, 2000; 2006). Somente assim, a associação pode construir uma unidade mínima para vocalizar e defender interesses, transformando-os em um projeto político comum. Contudo, os grupos nunca são objetos de representação como unidades ou como agregados homogêneos, já que são constituídos por indivíduos com diferentes e complexas experiências, moldadas por alguma consciência compartilhada de pertencimento (FRASER, 2003; GUTMANN, 2003). A diversidade dos surdos brasileiros é muito grande, sendo que há profundas divergências entre seus anseios, suas necessidades e concepções acerca do que é uma boa vida, conforme discutiremos a seguir.

\section{ORKUT E CONVERSAÇÕES COTIDIANAS: DISPUTAS PARA O PROCESSAMENTO DE DETALHES DO BEM COMUM}

A conversação que escolhemos analisar encontra-se presente na comunidade "Surdos, Oralizados", do sítio de relacionamentos Orkut. Essa comunidade pode ser considerada bastante ativa, pois em quatro anos de existência conta com um alto número de discussões (aproximadamente 800 tópicos), além de uma quantidade grande (3 897) de participantes. A comunidade reúne surdos oralizados, que se autodenominam capazes de "falar e entender ' $n$ ' coisas por leitura labial". O objetivo é discutir assuntos voltados para a "problemática da surdez", além de "informar e participar de vários temas que envolvam assuntos problemáticos comuns dos surdos oralizados na so- ciedade brasileira" e integrar socialmente todos os surdos por acreditarem "que é a melhor forma de uma vida plena e feliz". Há, porém, uma ressalva na página principal: "P.S: Que fique bem claro: É uma comunidade dos SURDOS ORALIZADOS, logo o foco será sobre a problemática dos surdos oralizados. Não estamos interessados em discutir LIBRAS na educação inclusiva ou especial por não fazer parte do cotidiano dos surdos oralizados. Todos são bem-vindos, desde que se respeite o propósito da comunidade! NÃO ESTAMOS INTERESSADOS EM LIBRAS! MSGS com foco em LIBRAS não serão toleradas".

O tópico "Oralização"8 é proposto por uma fonoaudióloga que reclama que está "perdendo clientes para a Libras". O comentário dessa profissional foi suficiente para suscitar uma longa discussão acerca da relevância da língua de sinais e da oralização. Esse fórum durou aproximadamente um mês, mas a participação concentrou-se principalmente em uma semana específica, o que demonstra um acirramento das questões em um determinado período.

\section{V.1. Intercâmbio de narrativas: experiências em choque}

Como apontado anteriormente, os testemunhos de vida são invocados de maneira a compartilhar experiências, traçar afinidades coletivas e pontos de convergência entre as histórias (YOUNG, 2000). O intercâmbio de narrativas apontado seria uma maneira de conectar situações particulares a contextos públicos. Complementando o argumento de Young, é importante destacar que a abertura das histórias à interpretação tende a encorajar falantes e ouvintes a extrair lições das experiências pessoais - principalmente quando os relatos possuem fortes conclusões normativas (uma "moral" clara) -, e podem, assim, suscitar reflexões críticas ou contestações. Na medida em que o contar histórias apresenta determinados pontos de vista e julgamentos, essa forma de comunicação pode motivar outras pessoas a acionar vivências diferentes, a fim de contestar aquelas experiências particulares e a falsa pretensão de universalidade que elas carregam consigo. Os testemunhos podem, assim, desencadear debates ou

8 O tópico teve 283 postagens (participações), que se iniciaram em 14 de maio de 2006 e terminaram em 25 de junho de 2006. 
motivar outros a contarem histórias com uma moral nitidamente diferente.

No tópico "Oralização", algumas mães contam suas experiências e identificam problemas comuns sobre a criação dos filhos surdos.

Lúcia: “[...] Minha filha é surda e eu, como mãe, escolhi para ela a oralização [...]. Sinceramente não a quero usando libras [...] sou ouvinte e sei como a sociedade DISCRIMINA SIM, qualquer coisa que fuja do 'normal. [...] O ser humano não é ensinado desde criança a lidar com nada que fuja do 'tradicional' [...]. Quero minha filha falando o mais próximo possível de um ouvinte, ela sabendo se virar bem quando eu morrer, [...] quero que ela não sofra TANTA discriminação, quero que ela não passe nada disso que eu passei, porque não é fácil olhar para o ser que vc mais ama na vida e ver isso [...]. Se eu pudesse, daria minha audição inteirinha para ela... [...] Minha bebê hoje tem 1 ano e 7 meses, descobri ainda na maternidade e desde então, minha vida virou uma corrida atrás de médicos, fonos, surdos, implantados, etc... Sinceramente, se há condição de oralizar, acho RIDÍCULA essa conversinha que o surdo prefere a libras, etc... Pq é mais fácil? Oras... É mais fácil não aprender a ler e escrever corretamente então... Por isso nós deixamos de estudar? De aprender??? Perdoem-me os defensores da libras, mas acho uma hipocrisia muiiito grande isso tudo... Só acho muito válido SIM a libras, qdo não há forma de oralização, ou se a oralização não fôsse possível em cada caso [...]".

Daniela: "Sou mãe de uma menina surda oralizada, graças à Deus. Penso q se existe essa possibilidade para eles se comunicarem pq não tentar... não é fácil, exige muito da mãe, da fono,... tardes inteiras trabalhando, férias, tempo integral, mas vale à pena. Hj ela fala muito bem, quase não se percebe q ela tem surdez profunda e severa, mas usa libras com os amigos q não são oralizados. Minha opinião é q deve se tentar de tudo para oralizar. Não tenho o menor preconceito".

Os testemunhos, nesse caso, visam sustentar um claro posicionamento a favor da oralização. São mães que julgam que o melhor para seus filhos é a comunicação por meio da fala, como meio de fugirem do preconceito e para que eles adquiram autonomia ao longo da vida. A peregrinação entre fonoaudiólogos, médicos, psicólogos e educadores exige muita dedicação e o processo de adaptação é doloroso, mas o esforço, para elas, compensa: "Quero minha filha falando o mais próximo de um ouvinte". A língua de sinais, no primeiro relato, é criticada veementemente: "Sinceramente, se há condição de oralizar, acho RIDÍCULA essa conversinha que o surdo prefere a libras". No caso de Daniela, a Libras é relegada a segundo plano: "Minha opinião é que deve se tentar de tudo para oralizar". Uma das mães entende que a comunicação por Libras é um comodismo, devido ao fato de a comunicação gestual ser mais "fácil".

Os testemunhos apresentados acima revelam certas assunções - a falta de audição como um defeito ou como algo anormal que precisaria ser consertado; a superioridade da língua oral sobre a de sinais no que diz respeito à plena compreensão cognitiva e à comunicação efícaz com outros; a necessidade de oralização para a auto-realização da pessoa e para a conquista da autonomia individual. No fórum do Orkut, diversos participantes mobilizam opiniões contrárias para contestar essas premissas. As histórias são rejeitadas não porque carecem de evidências, mas porque as recomendações não se mostram válidas para todos ou "crível" diante da experiência de outros.

Mara: "[Muitos] surdos tiveram a felicidade de se encontrar e se comunicar melhor com a Libras. Eu que sou oralizada, aprendi muitas palavras novas, graças à Libras, que muito me ajudou. E na faculdade consigo entender todo mundo e não finjo mais que estou entendendo, graças à minha intérprete que traduz tudo o que todos falam. Conheço muitos surdos não oralizados que passaram na faculdade... estamos evoluindo mesmo. Até minha família que era contra a Libras, hj percebeu que eu realmente estou falando melhor com a Libras. Com os ouvintes eu falo normal e com os surdos sinalizo".

Carla: "Pela minha experiência de professora por 20 anos pode acontecer que muitos surdos que tiveram dificuldade com a oralização (sem entender significados das palavras aprendidas e oralizadas) e a cognição fica muito atrasada por falta de evolução natural de uma língua (uma língua que lhes permitam a fazer raciocínio e pensar sobre tudo na vida) então quando estes mesmos surdos vão aprender a libras eles passam a entender melhor o português".

Ambos os testemunhos procuram demonstrar por meio de situações práticas que a língua de sinais é um modo válido e valoroso de comunicação. O testemunho de Carla busca evidenciar por 
meio da experiência de vinte anos como professora surda que muitos surdos têm dificuldade com a língua portuguesa porque não tiveram uma linguagem assimilada no tempo certo e há casos malsucedidos de oralização que levam a esse atraso. Percebe-se que esses testemunhos são acionados de modo a contrapor-se às premissas sobre a surdez expressas anteriormente e a ampliar o horizonte de expectativas em relação ao uso da língua de sinais.

Nossa pesquisa evidencia que o intercâmbio de narrativas serve não apenas para expressar o compartilhamento de experiências comuns, mas também para provocar o dissenso e a avaliação de experiências claramente diferentes. Em outras palavras, o intercâmbio de narrativas tem também a função de contestar generalizações e princípios normativos conectados a certas experiências. Ao imaginar tais situações, as pessoas podem demonstrar seu entendimento de certas posições de que discordam e, em igual medida, oferecer entendimentos alternativos, baseados em experiências distintas. Nesses casos, os testemunhos tendem a articular-se com argumentos e podem contribuir para a configuração de opiniões sobre questões controversas, conforme exploraremos na seção seguinte.

\section{V.2. A defesa da legitimidade de determinada rei-} vindicação: debates acirrados

Os testemunhos, por si mesmos, como apontado anteriormente, nem sempre são suficientes para evidenciar valores e premissas. Sem que se conecte a experiência narrada com algum "apelo a padrões universais" (DRYZEK, 2000, p. 69) ou a "razões e princípios amplamente compartilhados" (MILLER, 2002) os ouvintes não têm como saber qual a representatividade daquela experiência, nem como discernir entre os melhores remédios ou políticas para lidar com os danos sofridos, permanecendo o statu quo intacto (BENHABIB, 1996; DRYZEK, 2000). Questionamentos e disputas entre pontos de vista divergentes podem processar noções de justiça e meios para aliviar os sofrimentos vivenciados. No tópico "Oralização", a controvérsia entre a língua de sinais e a oralização estabelece-se desde o início da conversação.

Lourdes: "AMEI ESTA COMUNIDADE, SOU DEFENSORA DA ORALIZAÇÃO. HÁ 40 ANOS TRABALHO COM SURDOS. ATUALMENTE
ESTOU PERDENDO MEUS CLIENTES PARA 'LIBRAS'. JÁALFABETIZEI ALGUMAS DEZENAS DE SURDOS, MUITOS FIZERAM $2^{\circ}$ grau e até Faculdade".

Manoel: "É interessante o que você observou. Mas se pensarmos um pouco, para os surdos de nascença, a língua materna será a gestual. Ainda mais porque, para eles, na qualidade de surdos, é mais fácil de aprender [...]”.

Observa-se que as duas opiniões polarizam-se de imediato: uma condena expressamente a língua de sinais e exalta o oralismo; a outra afirma que a Libras é a "língua materna" dos surdos, mais natural e fácil de aprender. Adiante, outra participante sustenta que a língua de sinais é um meio cômodo e mais fácil, usado como desculpa "para não aprender a ler e a escrever corretamente". Em resposta a isso, além de testemunhos, argumentos contrários e a favor começam a aparecer conectados a essas histórias de vida.

Manoel: "Digamos que seja mais fácil a Libras por ser 'cômoda'. Não quis dizer que todos os surdos irão aprendê-la, mas, sim que um código lingüístico visual para o surdo 'é sua língua materna' $[\ldots]$ "..

Luana: "Muitas pessoas como vcs que se acham que ser surdo e oralizado significa mais potente e superior que surdo que utiliza LIBRAS, e falam que todo oralizado cursam faculdade, como a primeira pessoa desse tópico disse! Eu acho muita arrogância [...]. Eu sou oralizada e uso LIBRAS, e curso faculdade... e muitos surdos que usam LIBRAS cursam faculdades, de onde está a inferioridade deles? Na verdade LIBRAS é importante, e foi importante para mim tbm na faculdade!".

Rubens: "Não me considero superior a ninguém. Apenas defendo a oralização como o melhor caminho para o surdo se integrar na sociedade sem depender de ninguém. Você por exemplo, depende de intérpretes para captar o que os professores falam. Nada contra isso, mas eu não curto essa coisa. Primeiro: por que o mundo que está ali não funciona assim. Segundo: cria uma dependência extrema sua com o intérprete. No dia que não tiver intérprete, como você irá se virar?".

Várias controvérsias estabelecem-se. A primeira diz respeito ao entendimento de que a Libras dificulta a aprendizagem da língua portuguesa e pro- 
picia pouca abstração, em contraposição à idéia de que a Libras é a primeira língua. Se, no relato de Lúcia, a dificuldade dos surdos em aprender o Português é atribuída ao fato de eles terem aprendido a língua de sinais primeiro, e por serem comodistas, no depoimento de Carla, essa dificuldade é atribuída a uma ausência de linguagem nos primeiros anos de vida. Ao passarem por métodos de oralização na infância, muitos desses surdos aprendem apenas a repetir as palavras e adquirem uma linguagem e uma língua tardiamente, o que gera atrasos cognitivos. A segunda controvérsia delineada diz respeito à dependência versus autonomia conferida pelas duas formas de se comunicar. Enquanto, no testemunho da mãe, o surdo que não fala é dependente e não sabe "se virar", no relato de Mara, a Libras confere exatamente a oportunidade de crescimento intelectual e pessoal, e revela possibilidades de autonomia e de desenvolvimento cognitivo. Essa visão é, por sua vez, contestada pelo argumento de que o surdo que usa a língua de sinais fica dependente de um intérprete. A terceira controvérsia refere-se ao valor superior da língua oral e ao valor inferior da Libras. Manoel defende que a língua de sinais possui valor lingüístico, como outra língua qualquer. Luana reage contra o imaginário de superioridade que permeia o modo de vida de surdos oralizados e promove um tensionamento ainda maior da discussão.

A nossa pesquisa corrobora a concepção de que as conversações são desordenadas, sem metas claras, desestruturadas e entrecortadas de ironias, ofensas, retóricas, expressões estéticoafetivas e outros modos comunicativos (MANSBRIDGE, 1999; DAHLBERG, 2005; HABERMAS, 2005). Num determinado ponto do debate, um dos participantes desvia-se do tom argumentativo e chama a Libras de "porcaria":

Rubens: "Acho LIBRAS uma porcaria mesmo. É a minha opinião e PRONTO. Achar uma porcaria não quer dizer que acho que a língua seja inferior. Acho uma porcaria por que não me acrescenta em nada. É ofensivo isso?".

Ao expressar-se de modo rude, Rubens não se empenha em justificar sua opinião. Apenas diz que a língua não é inferior, mas que não serve em nada no seu cotidiano. A afronta foi suficiente para mobilizar o debate até o final, criando controvérsias acerca do sentido da surdez e levando à expulsão de alguns participantes da comunidade.
Juliana: "Sou obrigada a discordar de quem diz que Libras é porcaria. É efetiva para a comunicação, mesmo que seja em um grupo pequeno. Vamos dizer também que as línguas indígenas são porcarias porque são faladas por um menor número de pessoas?".

Rubens: "O engraçado é que pouquíssimas pessoas sabem utilizá-la. Se nem muitos surdos a usam, imagine os ouvintes. Realmente, a sociedade tem tanta peninha de nós e nos concedeu este presentão de grego!".

Pâmela: "Não é presentão de grego, prezado Rubens. É questão de direito, é soberano... se o Lula, o Presidente da República do Brasil, sancionou a lei, foi por força maior, por atender ao Povo Surdo, que tanto batalhou por sua língua, apesar desta língua ser uma 'porcaria' para você. Enfim é um presentão soberano, digno de orgulho para os muitos SURDOS, como eu, Carla, Mara, Diego... e tantos outros!”.

Daniela: "Olha este Decreto valeu, porém nem sequer se falou nos surdos oralizados... isso foi mal. Minha opinião é q se deve investir em centros auditivos com toda estrutura de fonos, palestras para a família, terapias grupal... criar uma Lei para as mães de deficientes trabalharem seis horas. Galera, a criança precisa muito da mãe e vcs não tem noção da diferença do surdo oralizado!”.

A luta por reconhecimento, moralmente motivada, desdobra-se, de modo concreto, por meio de diferentes modos comunicativos. Alguns autores apontam que questões que merecem ser defendidas ativam as paixões das pessoas, mas que, nem por isso, tornam-se impermeáveis ao exame racional (O' NEIL, 2002; DAHLBERG, 2005). Nota-se na seqüência de postagens acima um embate entre argumentos a favor e contra a língua de sinais, desencadeados por testemunhos. Juliana busca evidenciar uma luta por reconhecimento dos surdos como minoria lingüística que procura ser reconhecida na sua própria diferença comunicativa. Rubens, assumindo uma perspectiva "assimilacionista", defende que os surdos devem se esforçar para adaptarem-se à realidade da maioria. Para refutar essa visão e defender a legitimidade do uso da Libras são acionados argumentos legais, baseados nas reivindicações universalistas dos direitos do indivíduo, os quais se encontram na base do requerimento abstrato de igual tratamento. A Libras foi reconhecida legalmente pelo Governo Federal, fruto de reivindi- 
cações de uma coletividade e, por isso, constituise num direito. Nessa polêmica, cabe destacar que alguns participantes insistem em processar concepções éticas, defendendo que a Libras deve ser reconhecida não apenas porque se deve "respeito às diferenças" numa ordem democrática, mas porque a Libras é parte integral de um modo de vida de uma coletividade, sendo necessária ao florescimento humano de seus membros.

Ademais, alguns participantes mostram-se cientes de que aquilo que pode ser denominado de uma "institucionalização" de direitos corre o risco de promover uma "incorporação assimilacionista" (ALEXANDER, 2006), a qual é insatisfatória por não remover o estigma associado aos surdos, infringindo os requerimentos igualitários da justiça (FRASER, 2003; COOKE, 2009). Mais que isso, o relato de Daniela, ao afirmar que "este Decreto valeu, porém nem sequer se falou nos surdos oralizados", aponta que essa Lei, que os surdos sinalizados representados por suas associações tanto esperavam, não contempla todos os surdos brasileiros. A execução de emendas legais não pode ser tomada como um "estágio final" da luta por reconhecimento, como alguns autores vêm apontando (FORST, 2007; KOMPRIDIS, 2007; COOKE, 2009). Ainda que as leis funcionem como importantes meios de combater formas ilegítimas de desigualdade e exclusão, elas podem não contemplar todas as demandas legítimas existentes na sociedade. Além disso, elas não são suficientes para promover mudanças simbólicas e culturais no âmbito da vida cotidiana, no sentido de alterar orientações cognitivas e expectativas normativas arraigadas dos membros da sociedade. Isso remete ao processo de aprendizagem coletiva, discutido a seguir.

\section{V.3. Aprendizagem coletiva: a pluralidade}

Os testemunhos, ao revelarem premissas de fundo e apresentarem novos entendimentos sobre a experiência dos indivíduos, contribuem para um aprendizado coletivo (YOUNG, 2000). Tal aprendizado pode ser caracterizado como um passo na luta por reconhecimento e funcionaria como uma ponte semântica entre as questões subjetivas e a evolução da sociedade, seja para o aumento no grau de individuação, referindo-se à ampliação das oportunidades para alguém articular legitimamente os aspectos da própria personalidade, seja para maior inclusão social, dizendo respeito à expansão da inserção de sujeitos no círculo de mem- bros integrais da sociedade (HONNETH, 2003, p. 360). Se no sítio da Feneis há um discurso relativamente homogêneo sobre as aspirações dos surdos, suas metas e soluções propostas para os problemas coletivos, nas conversações do Orkut, a principal percepção é sobre a pluralidade de experiências e a irredutível particularidade de opiniões, de concepções de boa vida e projetos pessoais. Pode-se dizer que a percepção mesma dessa pluralidade é importante para que os sujeitos concebam-se em sua singularidade, de modo relacional, dentro de uma comunidade política. Esse é um aprendizado importante para a prática da cidadania democrática, uma vez que permite compreender, de modo prático, a legitimidade de reivindicações conflitantes para a auto-realização de sujeitos que abraçam projetos de vida concorrentes.

Nas análises do fórum "Oralização", encontramos um relato bastante expressivo, feito por Maria: "Eu entendo o porque de vc ficar meio bravo... É que, às vezes, os que defendem a Libras querem convencer todos os surdos a adotá-la. Eu também não concordo que a língua 'natural dos surdos' seja a Libras (se isto fosse verdade não haveria tantos surdos bem oralizados). Mas também sei, que para alguns surdos, ela se torna a sua única opção de comunicação. Entrei nesta comunidade porque sou a favor do Oralismo, mas até estou aprendendo com este 'debate' Libras X Oralismo!".

A afirmação "até que estou aprendendo com este "debate" revela que, de alguma maneira, as discussões ajudam no entendimento de questões outrora desconhecidas, como relata Carmen: "Estou achando muito válida toda essa discussão e estou aprendendo bastante ao ler a diversidade de pontos de vista e de histórias de vida. Acho que ainda há mais na realidade de cada um a ser analisada do que nossos discursos ideológicos, mas estou aprendendo... Pena não podermos ter aqui, a opinião de tantos outros surdos que ainda não têm, por razões de contextos, o domínio do português e da escrita, mas acredito que ainda chegaremos lá!"”.

A luta sobre o que significa reconhecer e ser reconhecido não chega a um estado final ou a um estado perfeito de reconhecimento (HONNETH, 2003; FORST, 2007; COOKE, 2009). Em vez disso, pressupõe um processo contínuo de discussão e aprendizagem coletiva - novas formas de institucionalização e desacordos subseqüentes. 


\section{CONCLUSÕES}

A luta pelo reconhecimento não pode ser instrumentalizada, pois pressupõe a agência dos sujeitos na vida prática em contextos diversos. Nossa pesquisa filia-se a um conjunto de estudos que defendem que a Internet amplia as oportunidades de comunicação e os recursos para que grupos e indivíduos que sofrem injustiças possam tornar visíveis interesses e aspirações de modo relativamente autônomo. Entendemos que a investigação dessas vozes marginalizadas em dois ambientes virtuais distintos nos proporcionou uma rica comparação.

Tanto no sítio da Feneis quanto no sítio de relacionamentos foi possível identificar a busca por engendrar novos sentidos na gramática moral da sociedade. Entretanto, há algumas distinções que devem ser levadas em conta. No sítio da Feneis, a comunicação é dirigida a um "outro presumido", as frases e as expressões utilizadas carregam consigo fortemente o olhar e o posicionamento do outro; revelam premissas e valores contra os quais se quer lutar. Este outro presumido que se coloca como destinatário do conteúdo do sítio é exatamente aquele que entende os surdos como incapazes, inferiores, analfabetos funcionais, com dificuldades de aprendizado e capazes apenas de exercerem atividades braçais. A voz associativa demonstra um ponto de vista definido de determinada instituição e apresenta um discurso relativamente homogêneo que se coloca frente à esfera pública de discussão.

O sítio, por meio dos seus testemunhos, confere grande ênfase: 1) à presença de histórias de superação, apontando o sucesso sobre as dificuldades; 2) à defesa da língua de sinais; e 3 ) ao orgulho de ser surdo. Além de os testemunhos serem muito parecidos, tendem a confirmar a existência de uma cultura e de uma identidade surdas como valorosas e dignas. Os questionamentos sobre se isso é válido ou não são subsumidos. Para que a associação tematize questões na esfera pública, represente e defenda pontos de vista, ela precisa eliminar a ambigüidade de valores e a dispersão de interesses. A multiplicidade de reivindicações e opiniões dificilmente poderia configurarse como algo passível de ser defendido como de interesse geral.

A heterogeneidade dos surdos brasileiros, que não encontra lugar no sítio da Feneis, é deflagrada no Orkut. Esse é um ambiente virtual que dá espaço para as opiniões discordantes e para as contestações existentes na sociedade. Diferentemente do sítio, em que os testemunhos e argumentos são publicados de maneira estática e o outro é presumido, no Orkut esse outro está presente de maneira palpável na dinâmica do debate. Os participantes da conversação posicionam-se ativamente frente aos proferimentos, aos juízos e às recomendações uns dos outros. Isso reforça o nosso pressuposto de que as lutas por reconhecimento ganham expressão - nos sítios - de modos distintos.

Todos os temas dos testemunhos expostos no sítio da Feneis também puderam ser encontrados nas histórias de vida acionadas no sítio de relacionamento. Contudo, o intercâmbio de narrativas evidencia que os participantes expressam distintas experiências, valores e concepções de boa vida. Nas conversações do Orkut, as pessoas freqüentemente se valem de suas histórias de vida, sendo que as premissas desses testemunhos motivaram discussões sobre: os ganhos e os prejuízos da língua de sinais e do oralismo; o melhor meio para a conquista da autonomia individual e as restrições e oportunidades da convivência nos ambientes da escola e do trabalho; a dependência ou não de intérpretes; o valor, mesmo, da língua de sinais.

Nosso estudo mostrou que o contar estórias não é suficiente para evidenciar a legitimidade de certas demandas. Mesmo em discussões calorosas e apaixonadas, argumentos também são mobilizados, na tentativa de justificar as preferências dos sujeitos e ampliar o conhecimento a respeito de visões diferentes e possíveis soluções para os problemas enfrentados (HABERMAS, 1982; 1997; BENHABIB, 1996; DRYZEK, 2000). Sob o ponto de vista teórico, nosso estudo corrobora a idéia de que as conversações - ainda que "espontâneas, desestruturadas e sem metas claras" (CONNOVER, SEARING \& CREWE, 2002, p. 24), ou como uma "aventura intelectual não ensaiada" (BARBER, 1984, p. 184) - contribuem para que os cidadãos passem a ter mais clareza sobre as próprias preferências, testem suas opiniões e, ainda, adquiram competências políticas e capacidades discursivas (WYATT, KATZ \& KIM, 2000; CONNOVER, SEARING \& CREWE, 2002). Os testemunhos são formas relevantes de comunicação nesse processo. 
A pesquisa futura sobre vozes marginalizadas na Internet deve examinar em maior profundidade e com maior grau de detalhamento diferentes ambientes virtuais e distintos tipos de comunicação exercidos online. A homogeneidade do discurso de uma organização civil presente no sítio, com evidente intuito de "representar" e "agir em nome" de uma coletividade contrasta com os "diálogos múltiplos", exercidos de modo relativamente livre e espontâneo, no Orkut. Os testemunhos apresentados no sítio institucional aparentemente apresentam uma moral clara, sustentando um projeto político comum, mas, quando apresentados no Orkut, eles desencadeiam as mais diversas disputas entre as pessoas afetadas e concernidas para interpretar valores, princípios e bens e, assim, negociar o que conta como legítimo e válido, numa dada situação. Os diferentes modos de participação e engajamento dos cidadãos, dentro de específicos ambientes virtuais na Internet, são importantes processos, que se imbricam na luta por reconhecimento na contemporaneidade.

Regiane L. O Garcêz (regianelog@yahoo.com.br) é Mestre em Comunicação Social pela Universidade Federal de Minas Gerais (UFMG) e Professora nessa mesma instituição.

Rousiley C. M. Maia (rousiley@fafich.ufmg.br) é Doutora em Ciência Política pela University of Nottingham, na Inglaterra, e Professora do Departamento de Comunicação Social da Universidade Federal de Minas Gerais (UFMG).

\section{REFERÊNCIAS BIBLIOGRÁFICAS}

ALEXANDER, J. 2006. The Civil Sphere. New York : Oxford University.

BAKHTIN, M. 1986. Marxismo e filosofia da linguagem. São Paulo : Hucitec.

BARBER, B. 1984. Strong Democracy : Participatory Politics for a New Age. Berkeley: University of California.

BENHABIB, S. 1996. Toward a Deliberative Model of Democratic Legitimacy. In : BENHABIB, S. Democracy and Difference. Princeton : Princeton University.

BLACK, L. 2008. Deliberation, Storytelling and Dialogic Moments. Communication Theory, Urbana, v. 18, p. 93-116.

CONOVER, P.; SEARING, D. \& CREWE, I. 2002. The Deliberative Potential of Political Discussion. British Journal of Political Science, Cambridge, v. 32, n. 1, p. 21-62.

COOKE, M. 2009. Beyond Dignity and Difference : Revisiting the Politics of Recognition. European Journal of Political Theory, Birmingham, v. 8, n. 1, p. 76-95.

DAHLBERG, L. 2005. The Habermasian Public Sphere : Taking Difference Seriously? Theory and Society, v. 34, n. 2, p. 111-136, Apr.

DRYZEK, J. 2000. Deliberative Democracy and Beyond : Liberals, Critics, Contestations.
Oxford : Oxford University.

FORST, R. 2007. First Things First : Redistribution, Recognition and Justification. European Journal of Political Theory, Birmingham, v. 6, n. 3, p. 291-304.

FRASER, N. 1997. From Distribution to Recognition? Dilemmas of Justice in a 'Postsocialist' Age. In : FRASER, N. Justice Interruptus : Critical Reflections on the 'Postsocialist' Condition. London : Routledge.

2003. Social Justice in the Age of Identity Politics : Redistribution, Recognition, and Participation. In : HONNETH, A. \& FRASER, N. Redistribution or Recognition - a PoliticalPhilosophical Exchange. New York : Verso.

GUEDES，O. 2002. New Technologies, Democracy and Social Movement. Paper. 2001 Bugs - Globalism and Pluralism, Montreal.

GUTMANN, A. 2003. Identity in Democracy. Princeton : Princeton University.

HABERMAS, J. 1982. A transformação estrutural da esfera pública. Rio de Janeiro : Tempo Brasileiro.

1997. Direito e democracia : entre facticidade e validade. V. I. Rio de Janeiro : Tempo Brasileiro.

2005. Concluding Comments on Empirical 
Approaches to Deliberative Politics. Acta Politica, v. 40, n. 3, p. 384-392, Sep.

HONNETH, A. 2003. Luta por reconhecimento : a gramática moral dos conflitos sociais. São Paulo : 34 .

KIM, J. \& KIM, E. 2008. Theorizing Dialogic Deliberation : Everyday Political Talk as Communicative Action and Dialogue. Coтmunication Theory, Urbana, v. 18, p. 51-70.

KOMPRIDIS, N. 2007. Struggling Over the Meaning of Recognition : a Matter of Identity, Justice or Freedom. European Journal of Political Theory, Birmingham, v. 6, n. 3, p. 277-289

LANGMAN, L. 2005. From Virtual Public Spheres to Global Justice : a Critical Theory of Internetworked Social Movements. Sociological Theory, Washington, DC, v. 23, n. 1, p. 42-74.

MANSBRIDGE, J. 1999. Everyday Talk in Deliberative System. In : MACEDO, S. (ed.). Deliberative Politics : Essays on Democracy and Disagreement. Oxford : Oxford University.

MELUCCI, A. 1996. Challenging Codes: Collective Action in the Information Age. Cambridge : Cambridge University.

MILLER, D. 2002. Is Deliberative Democracy Unfair to Disadvantaged Groups? In : D’ENTREVES, M. (ed.). Democracy as Public Deliberation : New Perspectives. Manchester : Manchester University.

MITRA, A. 2001. Marginal Voices in Cyberspace. New Media \& Society, London, v. 3, n. 1, p. 29-48.

O'NEILL, J. 2002. The Rhetoric of Deliberation : Some Problem in the Kantian Theories of Deliberative Democracy. Res Publica, v. 8, p. 249-268.

PALCZEWSKI, C. 2001. Cyber-Movements, New Social Movements, and Counterpublics. In : ASEN, R. \& BROUWER, D. (orgs.). Counterpublics and the State. New York: State University of New York.

PERLIN, G. 1998. História de vida surda : identidades em questão. Porto Alegre. Dissertação (Mestrado em Educação). Universidade Federal do Rio Grande do Sul.
2002. História dos surdos. In : ABREU, A. (org.). Caderno Pedagógico : Pedagogia para surdos. Florianópolis : UDESC.

.2003. Ser e o estar sendo surdo : alteridade, diferença e identidade. Porto Alegre. Tese (Doutorado em Educação). Universidade Federal do Rio Grande do Sul.

POLLETA, F \& LEE, J. 2006. Is Telling Stories Good for Democracy? Rhetoric in Public Deliberation after 9/11. American Sociological Review, Washington, D. C., v. 71, n. 5, p. 699723.

SACKS, O. 1989. Vendo vozes : uma viagem pelo mundo dos surdos. São Paulo : Cia das Letras.

SCHEUFELE, D. 2000. Talk or Conversation? Dimensions of Interpersonal Discussion and their Implications for Participatory Democracy. Journalism and Mass Communication Quarterly, Columbia, v. 77, p. 727-743.

SELIGMANN-SILVA, M. 2006. Testemunho e a política da memória : o tempo depois das catástrofes. Projeto História, São Paulo, n. 30, p. $31-78$, jun.

SKLIAR, C. (org.). 1998. A surdez : um olhar sobre as diferenças. Porto Alegre : Mediação.

STROBEL, K. 2006. Visão histórica sobre a in(ex)clusão dos surdos. Educação Temática Digital, Campinas, v. 7, n. 2, p. 244-252, jun.

TAYLOR. C. 1992. El multiculturalismo y "la política del reconocimiento". México : Fondo de Cultura Econômica.

URBINATI, N. 2000. Representation as Advocacy : a Study of Democratic Deliberation. Political Theory, Evanston, v. 28, n. 6, p. 758786.

2006. Representation and Democracy : Principles and Genealogy. Chicago : Chicago University.

WYATT, R.; KATZ, E. \& KIM, J. 2000. Bridging the Spheres : Political and Personal Conversation in Public and Private Spaces. Journal of Communication, Oxford, v. 50, n. 1, p. 71-92, Winter.

YOUNG, I. 2000. Inclusive Political Communication. In : YOUNG, I. Inclusion and Democracy. New York : Oxford University. 


\section{OUTRAS FONTES}

BRASIL. 2002. Lei n. 10 436, de 24 de abril de 2002. Dispõe sobre a Língua Brasileira de Sinais - Libras e dá outras providências. Diário Oficial da União, Brasília, 25.abr. Disponível em : http://www.planalto.gov.br/ccivil_03/ Leis/2002/L10436.htm. Acesso em : 15.jan. 2008 .
FEDERAÇÃO NACIONAL DE INTEGRAÇÃO E EDUCAÇÃO DE SURDOS. 2007. Sítio eletrônico. Disponível em : http:// www.feneis.com.br. Acesso em : 7.set.2007.

ORKUT. 2007. Fórum Oralização. Disponível em : http://www.orkut.com/Comm Msgs.aspx? $\mathrm{cmm}=60081 \& \mathrm{tid}=2464506677$ 470568464. Acesso em : 12.dez.2007. 


\section{STRUGGLES FOR THE RECOGNITION OF THE DEAF THROUGH THE INTERNET: THE POLITICAL EFFECTS OF TESTIMONY}

\section{Regiane L. O. Garcêz and Rousiley C. M. Maia}

In this article, we investigate the opportunities that the Internet offers for minority or marginalized groups to express themselves, focusing on the struggles for recognition that deaf people have initiated. We focus particularly on the political representation of interests by the leadership of this social movement and contentions that have arisen within this collectivity regarding definition of the "common good". The material we analyze is the testimony provided through two different internet spaces: the website of an association of the deaf - the Federação Nacional de Educação e Integração dos Surdos (National Federation for the Education and Integration of the Deaf (Feneis)) - and a discussion forum belong to a social portal (Orkut). Testimonies on the Feneis site show a relatively homogeneous public discourse - with definitions of well-being and projections of future goals - that seek to demonstrate the existence of an "us", to mediate the formation of opinion and express political will. Analysis of the Orkut forum shows that those affected and concerned, in discussing their individual aspirations and interests, diverge considerably regarding details of the common good. We argue that the use of testimonies produces different effects regarding interchange of experience, legitimacy of demands and collective learning, within different virtual environments.

Keywords: Internet; recognition; testimony; the deaf; minority groups. 


\section{LUTTES POUR LA RECONNAISSANCE DES SOURDS SUR INTERNET: EFFETS POLITIQUES DU TÉMOIGNAGE}

Regiane L. O. Garcêz et Rousiley C. M. Maia

Dans cet article, nous enquêtons sur les possibilités qu'Internet offre aux groupes minoritaires ou marginaux de s'exprimer, en soulignant la lutte menée par des personnes sourdes. Nous mettons au point, en particulier, la représentation politique d'intérêts des leaders de ce mouvement social et les contestations autour des définitions de « bien commun » par des membres de cette collectivité. A cet effet, nous analysons les témoignages de vie délivrés dans deux environnements virtuels différents sur Internet : le site électronique d'une association de sourds - la Federação Nacional de Educação e Integração dos Surdos (Feneis) - et dans un forum d'un réseau relationnel virtuel (Orkut). Les témoignages du site Feneis dévoilent un discours public à peu près homogène - avec des définitions de bien vivre et des projets futurs - qui cherche à montrer l'existence d'un « nous » et à concilier la formation de l'opinion et l'expression de la volonté politique. Par ailleurs, l'analyse du forum de l'Orkut met en évidence que les personnes concernées, lorsqu'elles discutent de leurs aspirations individuelles et de leurs intérêts, produisent une grande fragmentation sur les détails du bien commun. Nous prônons que, dans des environnements vituels différents, le recours au témoignage entraîne des effets divers en ce qui concerne l'échange d'expériences, la défense de la légitimité des revindications et l'apprentissage collective.

MOTS-CLÉS : Internet; reconnaissance; témoignage; sourds; groupes minoritaires. 